\title{
THE EFFECT OF 3 DIFFERENT EXERCISE APPROACHES ON NECK MUSCLE ENDURANCE, KINESIOPHOBIA, EXERCISE COMPLIANCE, AND PATIENT SATISFACTION IN CHRONIC WHIPLASH
}

Gunnel Peterson, Maria Landén Ludvigsson, Shaun P. OLeary, Asa M. Dedering, Thorne Wallman, Margaretha I. N. Jonsson and Anneli Peolsson

\section{Linköping University Post Print}

\section{Tweet}

N.B.: When citing this work, cite the original article.

Original Publication:

Gunnel Peterson, Maria Landén Ludvigsson, Shaun P. OLeary, Asa M. Dedering, Thorne Wallman, Margaretha I. N. Jonsson and Anneli Peolsson, THE EFFECT OF 3 DIFFERENT EXERCISE APPROACHES ON NECK MUSCLE ENDURANCE, KINESIOPHOBIA, EXERCISE COMPLIANCE, AND PATIENT SATISFACTION IN CHRONIC WHIPLASH, 2015, Journal of Manipulative and Physiological Therapeutics, (38), 7, 465-746.e4.

http://dx.doi.org/10.1016/j.jmpt.2015.06.011

Copyright: Elsevier

$$
\text { http://www.elsevier.com/ }
$$

Postprint available at: Linköping University Electronic Press

http://urn.kb.se/resolve?urn=urn:nbn:se:liu:diva-122438 


\section{EFFECTS OF THREE DiFFERENT EXERCISE APPROACHES ON NECK MuSCLE}

\section{ENDURANCE, KINESIOPHOBIA, EXERCISE COMPLIANCE, AND PATIENT}

\section{SATISFACTION IN CHRONIC WHIPLASH}

Gunnel Peterson, PT, MSc, ${ }^{1,2}$, Maria Landén Ludvigsson, PT, MSc, ${ }^{2,3}$, Shaun 0'Leary, PT, $\mathrm{PhD}^{4,5}$, Åsa Dedering, PT, Assoc. Prof ${ }^{6}$, Thorne Wallman, $\mathrm{MD}, \mathrm{PhD}^{1,7}$, Margaretha Jönsson, $\mathrm{PT}, \mathrm{MSc}^{8}$, Anneli Peolsson, Assoc. Prof ${ }^{2,4}$

${ }^{1}$ Centre for Clinical Research Sörmland, Uppsala University, Eskilstuna, Sweden

${ }^{2}$ Department of Medical and Health Sciences, Division of Physiotherapy, Faculty of Health Sciences, Linköping University, Linköping, Sweden

${ }^{3}$ Rehab Väst, County Council of Östergötland, Sweden

${ }^{4}$ NHMRC CCRE (Spinal Pain, Injury and Health), the University of Queensland, Brisbane, Australia

${ }^{5}$ Physiotherapy Department, Royal Brisbane and Women's Hospital, Queensland Health, Brisbane, Australia.

${ }^{6}$ Department of Neurobiology, Care Sciences and Society, Division of Physiotherapy, Karolinska Institutet and Department of Physical Therapy, Karolinska University Hospital, Sweden

${ }^{7}$ Uppsala University, Public Health \& Caring Sciences, Family Medicine \& Preventive Medicine Section, Uppsala, Sweden

${ }^{8}$ Prima Rehab, Herrgärdet Health Care Center, County Council of Västmanland, Sweden

This study was funded by the Swedish government in cooperation with the Swedish Social Insurance Agency through the REHSAM foundation, Centre for Clinical Research Sörmland at Uppsala University Sweden and Uppsala-Örebro Regional Research Council Sweden. 
This study was approved by the Regional Ethical Review Board in Sweden and was conducted according to the Declaration of Helsinki. 


\section{AbSTRACT}

2 Objectives: The purpose of this study was to compare the effects of three different exercise

5 Methods: This prospective randomized clinical trial included 216 individuals with chronic approaches on neck muscle endurance (NME), kinesiophobia, exercise compliance, and patient satisfaction in chronic whiplash.

whiplash. Participants were randomized to one of three exercise interventions: neck-specific exercise (NSE), neck-specific exercise combined with a behavioral approach (NSEB), or prescribed physical activity (PPA). Measures of ventral and dorsal NME (endurance time in seconds), perceived pain following NME testing, kinesiophobia, exercise compliance, and patient satisfaction were recorded at baseline and at the three- and six-month follow-ups.

Results: Compared to individuals in the PPA group, participants in the NSE and NSEB groups exhibited greater gains in dorsal $\operatorname{NME}(P=.003)$, greater reductions in pain following NME testing $(\mathrm{P}=.03)$ and more satisfaction with treatment $(P<.001)$. Kinesiophobia and exercise compliance did not significantly differ between groups $(P>.07)$.

Conclusion: Among patients with chronic whiplash, a neck-specific exercise intervention (with or without a behavioral approach) appears to improve neck muscle endurance.

Participants were more satisfied with intervention including neck-specific exercises than with the prescription of general exercise.

Key Indexing Terms: Exercise; Neck Pain; Whiplash; Rehabilitation 
Among people who suffer a whiplash injury, approximately 50\% report symptoms that persistent for over 1 year, ${ }^{1}$ resulting in substantial costs to both the individual and society. ${ }^{2,3}$ Persistent pain and disability in chronic whiplash appears to be associated with impaired motor function, ${ }^{4-6}$ that includes deficient neck muscle endurance ${ }^{7}$ and altered function in deep and superficial neck muscles ${ }^{5}$ that may negatively affect the physical support of the cervical spine. ${ }^{8-11}$ The cervical spine is heavily dependent on neck muscles for its physical support ${ }^{9,10}$ and thus, specific neck muscle training is recommended within the management approach of patients with a whiplash-associated disorder (WAD). ${ }^{12}$ However, although there is strong evidence that specific neck muscle training is effective in managing idiopathic neck pain, ${ }^{13}, 14$ such training has shown only modest benefits in WAD. ${ }^{15}, 16$ Therefore, specific neck exercises are often not utilized in this population. It is more commonly suggested that patients with WAD remain physically active using a more general exercise approach, which has shown positive effects in modulating ${ }^{17}$ and preventing ${ }^{18,19}$ chronic pain. However, the effects of general exercise have to our knowledge, not specifically been studied in cases of chronic WAD. may be counteracted by incorporating a behavioral approach to neck-specific exercise. Behavioral approaches - that included progressive goal attainment strategies and pain physiology education in an attempt to modify inappropriate pain beliefs - have previously been used in conjunction with exercise to modify fear of pain and (re)injury related to 
47 enhance a patient's capacity to undertake daily activities. ${ }^{24,}{ }^{25}$ However, randomized controlled trials investigating behavioral approaches in chronic WAD management have yielded at best only modest improvements. ${ }^{15,26,27}$ Previous studies have been limited by methodological factors, such as small sample size ${ }^{26}$ and poorly standardized treatment. ${ }^{15}$ Thus, further investigation of the potential additional benefits of a behavioural approach to neck-specific exercise in chronic WAD is warranted.

The present study aimed to compare the effects of a neck-specific exercise intervention with and without the addition of a behavioral approach to that of a general exercise intervention in patients with chronic whiplash. Results were evaluated with regard to improved neck muscle endurance, perceived pain in response to endurance testing, kinesiophobia, exercise compliance, and patient satisfaction. We hypothesized that the neckspecific exercise interventions with or without the behavioral approach would result in greater improvements in all outcomes compared to general exercise, and that the addition of a behavioral approach would result in greater improvements than seen with neck-specific exercise alone.

\section{METHODS}

\section{Design}

Here we analyzed the secondary outcomes of a multicenter, prospective, randomized controlled trial (RCT) (ClinicalTrials.gov NCT01528579) with blinded outcome assessments conducted in six counties in south-east Sweden. ${ }^{28}$ The primary outcome measure of the RCT was neck disability index, which is reported elsewhere. ${ }^{29}$ This study was approved by the Regional Ethical Review Board, and was conducted in accordance with the Declaration of Helsinki. 
Figure 1 shows the flow diagram of participant recruitment and retention. The recruited participants all reported ongoing symptoms associated with a whiplash injury that occurred six months to three years prior to study entry, and were diagnosed with WAD grade II (neck pain and musculoskeletal signs) or III (neck pain plus neurological signs). ${ }^{30}$ Other inclusion criteria were an average neck pain intensity over the past week of $>20 \mathrm{~mm}$ using a visual analogue scale $(\mathrm{VAS})^{31}$ and/or a score of $>20 \%$ on a Neck Disability Index (NDI), ${ }^{32}$ an age of between 18-63 years, and fluency in Swedish. Participants were excluded if they reported any of the following: signs of traumatic brain injury at the time of whiplash injury (loss of consciousness, retrograde and post-traumatic amnesia, disorientation, and confusion), previous serious neck pain causing sick leave of over one month during the 12-month period before their whiplash injury, previous serious neck trauma/injury, neuromuscular or rheumatologic disease, severe mental illness, current alcohol or drug abuse, or any condition that contraindicated their performance of exercise.

\section{Study Procedure}

Participant recruitment occurred between February 2011 and May 2012. Potential participants were identified via electronic medical records from health care registers and were subsequently recruited from primary health care centers, specialist orthopedic clinics, and hospital outpatient services. The first step of participant recruitment involved mailing an initial information and screening letter that contained basic study information, basic inclusion/exclusion criteria, VAS and NDI screening questionnaires, and a prepaid return envelope. Next, the apparently eligible respondents completed a telephone interview. Finally, individuals were subjected to a clinical examination by one of the study investigators to verify their diagnosis of WAD grade II or III. 

participating counties. These investigators attended practical sessions together prior to the

start of examinations and were trained to undertake the strict testing protocol. Each investigators skill in conducting the testing protocol was assessed by one of the principal researchers. Potential sources of bias were minimized as these investigators were blinded to the participants' intervention group allocation, and had no involvement in delivering the interventions to participants. An independent researcher randomly allocated the qualified participants using a computer generated list, and sent the participant's group allocation and contact details in a sealed opaque envelope to the treating physiotherapist. Informed consent was obtained twice from all participants: firstly during the telephone interview by one of the principal researchers, and again during the session in which baseline measures were recorded supervised by the investigator.

\section{Interventions}

The study interventions were delivered by physiotherapists practicing primary health care in six different counties, thus minimizing geographical issues for participants attending intervention sessions. The behavioral approach was considered to be basic and performable by experienced physiotherapists with some previous knowledge of behavioral approaches. Prior to study commencement, the physiotherapists received one day of theoretical and practical training by the project leaders. The project leaders also provided a contact point for the therapists if they required further advice regarding the interventions. Participants in each intervention group underwent a physical examination performed by the physiotherapist, and filled in a diary describing the home exercises performed during the treatment period.

Following completion of the intervention period, all participants in all three groups were encouraged to continue their exercises outside the physiotherapy clinic. The physiotherapists 
in the neck-specific exercise (NSE) and neck-specific exercise with behavioral approach

122

(NSEB) interventions followed a standardized (but different) exercise protocol (see Table 1 for summary), with flexibility to modify the program on individual basis if required. The physiotherapists recorded the exercises that the participants' completed at the clinic in a diary.

\section{Neck-Specific Exercise (NSE) Group}

The exercise program was supervised by a physiotherapist twice weekly for 12 weeks, with additional home exercises. The participants were given information concerning anatomical and physiological factors relevant to symptoms following whiplash injury, including the need for postural awareness (Appendix A). The exercises were initially low load and targeted at the deeper ventral ${ }^{12}$ and dorsal neck muscle layers (Appendix B). At weeks two to three, the patients commenced exercises designed to improve neck muscle endurance using weighted pulleys and guild boards (Appendix C). These exercises were continually progressed within the participant's symptom tolerance. Participants in this exercise intervention group were instructed to avoid pain aggravation during exercise.

\section{Neck-Specific Exercise with Behavioral Approach (NSEB)}

The exercises performed by participants in this group were identical to those performed by the NSE group. During the first two weeks, participants formulated specific activity goals and received education specifically aimed at inducing behavioral change (Appendix A). To accommodate the behavioral component of their intervention, the commencement of gym exercises (Appendix C) was delayed by two weeks compared to the NSE group. Also in contrast to the NSE group, participants in the NSEB group were encouraged to continue their exercises despite pain, but to avoid a cumulative elevation of pain level over the duration of 
the program. If this occurred, the exercise parameters were adjusted to reduce the elevated

147 pain level.

\section{Prescription of Physical Activity (PPA)}

The participants in the PPA group had one or two appointments with the physiotherapist, which included a physical examination and motivational interview session (Appendix A). These initial meetings explored the participants' motivation for change and provided them with information regarding the benefits of physical activity. Each participant was provided with an individual physical activity program (for instance, general aerobic exercises). Based on the physical examination and the interview, the physiotherapist chose exercises that the participant was able to perform and was motivated to do. The program did not include neck-specific exercises. The exercises were performed at home or at a selected location outside of health care, such as a gym.

\section{Measurements}

Outcome measurements were recorded at baseline and at the three- and six-month follow-ups except for kinesiophobia, which was measured at baseline and six months. At the three- and six-month follow-ups, the participants were also asked whether they had experienced any further neck injuries or received any other interventions for their neck during the study period. The participants completed a questionnaire including the self-reported measurements at home prior the physical testing session. Neck muscle endurance tests were conducted by the investigators. 


\section{Ventral and Dorsal Neck Muscle Endurance}

The primary outcome was a measure of neck muscle endurance (NME) that has been previously reported to be of good reliability (ICC > 0.88). ${ }^{33} \mathrm{NME}$ was standardized and measured in seconds as previously described. ${ }^{34,35}$ For all participants, ventral NME was tested first. Ventral neck muscle endurance was measured with the patient supine, keeping their legs straight, arms positioned alongside the body, and head and cervical spine in a neutral position. Participants were given instructions to slightly nod, retract their chin, and raise their head just above the examination table, such that a small head lift was performed in slight upper cervical flexion. ${ }^{34}$ Dorsal NME was measured with the patient prone, keeping their legs straight, arms alongside the body, and head initially supported on the examination table. A load of $2 \mathrm{~kg}$ for women or $4 \mathrm{~kg}$ for men was applied to the head, and the participants were instructed to lift their head just above the examination table with the tip of the chin pointing at the floor, thus performing a slight extension of cervical spine. ${ }^{34}$

Participants were asked to maintain the test position for as long as possible and to stop the test by returning the head to rest on the examination table at the point of neck fatigue, or if they felt pain radiating into the arm. The participants were also instructed to stop the test if they experienced severe neck pain. For both tests, endurance was measured in seconds using a stopwatch. Before the official test trial, participants practiced the test (nod the chin in supine, chin pointing at floor and lifting the head without the weight in prone) for familiarization purposes. When necessary, the test leader verbally instructed the participants to correct their test position during the measurement.

\section{Perceived Neck Pain Intensity}

Immediately before and after the NME test, the pain intensity of the neck was measured using a VAS with a scale of $0 \mathrm{~mm}$ (no pain) to $100 \mathrm{~mm}$ (worst imaginable pain). ${ }^{31}$ 


\section{Kinesiophobia}

The participants reported their perceived fear of movement and (re)injury using the Tampa Scale for Kinesiophobia (TSK-11) short form and the two-factor model of the TSK11, comprising activity avoidance (TSK-AA) and somatic focus (TSK-SF). ${ }^{36}$ The TSK-11 includes 11 items that are each scored from 1 to 4, with higher scores indicating greater fear of movement and (re)injury. Subscale TSK-AA has 5 items with a possible total score ranging from 5 to 20, and the TSK-SF includes 6 items with a possible total score ranging from 6 to 24 .

\section{Patient Satisfaction}

At the six-month follow-up, the participants rated their satisfaction with the intervention by answering the question "How is your experience of the intervention for your neck pain?" using a seven-point Likert scale, from 1 (very dissatisfied) to 7 (very satisfied).

\section{Exercise Compliance}

Compliance to exercise was defined as at least $50 \%$ attendance to the recommended intervention sessions (all three groups) with the addition of basic information for the NSE group and least $50 \%$ of the behavioral components for the NSEB group. Completion rate was collected from the physiotherapist-completed diaries (NSE and NSEB groups) and participant completed exercise diaries (PPA group), (Appendix A).

\section{Statistical Analysis}

The study sample size was based on the primary outcome (NDI) of the RCT. ${ }^{28,29}$ To detect a minimal clinically important NDI reduction of $7 \%,{ }^{37}$ it was calculated that 63 participants per group were required. To account for drop-outs, a total of 216 participants 
were recruited. Statistical significance was set at an $\alpha$ level of 0.05 . The analysis was performed on an intention-to-treat basis, including all participants who completed each measurement.

All analyses were performed with the SPSS (version 20.0) statistical package. Group data at baseline were compared with one-way analyses of variance (ANOVA) or the KruskalWallis test for non-normally distributed data. For binary outcomes, the chi-square test was used. Drop-out analysis was performed by comparing the baseline variables between dropouts at six months and individuals who completed all outcome measurements.

To analyze the neck muscle endurance results, a linear mixed model was conducted with time (3 levels; baseline, 3 months, and 6 months), group (three levels; NSE, NSEB and PPA), and gender (2 levels; men and women) as fixed effects, and ventral or dorsal neck muscle endurance as the dependent variable. Included in the model were individuals with baseline data and at least one more measurement (three and/or six months). Statistics (P values) for the linear mixed model analyses were reported for the; overall change over time $\left(\mathrm{P}_{\mathrm{t}}\right)$; differences between groups $\left(\mathrm{P}_{\mathrm{g}}\right)$; differences between gender $\left(\mathrm{P}_{\mathrm{s}}\right)$; interaction between time and group $\left(\mathrm{P}_{t^{*} \mathrm{~g}}\right)$; interaction between time, group and gender $\left(\mathrm{P}_{\left.\mathrm{t}^{*} \mathrm{~g} *^{*}\right)}\right)$. For dorsal NME; the time* group*gender analysis showed non-significant differences between gender, so gender was excluded from the model. For ventral NME; there were significant differences between gender so post-hoc analyses were stratified for gender. The NME measurements were strongly positively skewed and variance significantly different (Levene's test $P<.05$ ); thus, all measurements were $\log$ transformed $(\log 10)$.

The perceived neck pain measurements were highly skewed, and therefore were analyzed using non-parametric tests. Between-group differences in neck pain, patient satisfaction and kinesiofobia (from the TSK-11 and both subscales) were analysed using Kruskal-Wallis tests and post-hoc comparisons were evaluated with the Mann-Whitney U test 
when indicated. A Friedman's test was used to determine within-group differences with respect to time, and the findings were further clarified using the Wilcoxon test.

Finally, the measurement of exercise compliance was dichotomized (compliant, noncompliant) according the attendance (defined as at least $50 \%$ attendance to the recommended intervention sessions) and analysed using a chi-square test.

\section{RESUlTS}

This study included 216 participants, including 142 women and 74 men with a mean age of 40 years (SD, 11.4 years). Of these participants, 123 were diagnosed with WAD grade II and 93 with WAD grade III. Baseline characteristics were similar between groups, except that the NSE group was generally younger and contained more females compared to the PPA group (Table 2). A total of 184 participants (85\%) were tested at three months and $165(77 \%)$ at six months. Participants who dropped-out, and those who completely fulfilled the intervention did not significantly differ in any baseline characteristic $(P>.10)$ or baseline measurements $(P>.26)$. The groups did not significantly differ in the occurrence of new neck injuries or in the receipt of additional treatment (outside that provided by the study) over the duration of the study (Table 3).

\section{Ventral and Dorsal Neck Muscle Endurance}

Data from the NME tests for both the ventral and dorsal muscles are shown in Table 4. For dorsal NME a total of 182 individuals were included in the linear mixed model and 185 participants for ventral NME. For dorsal NME there were no significant group*time*gender interaction effect $(\mathrm{F}=1.3, \mathrm{P}=.25)$ but a significant group-by-time interaction effect $(\mathrm{F}=4.1$, $P=.003)$, where both the NSE and NSEB groups $(\mathrm{F}=6.8$ to $5.5, \mathrm{P}<.05)$ improved in dorsal NME from baseline to six months compared to the PPA group $(\mathrm{F}=.42 \mathrm{P}=.66)$. 
271 For ventral NME, we found no significant interaction effects between group*time*gender (F $272=1.4, \mathrm{P}=.23)$ or group*time $(\mathrm{F}=1.8, \mathrm{P}=.13)$ but a significant group by gender interaction

273 effect $(\mathrm{F}=3.2, \mathrm{P}=.04)$ When stratified for gender, there were significant differences

274 between groups for men at six months $(\mathrm{F}=4.2, \mathrm{P}=.02)$, men in the NSE and NSEB groups 275 showed higher ventral NME compared to men in the PPA group.

Perceived neck pain

There were significant between-group differences in pain intensity; pain was decreased for the NSE group at three months $(\mathrm{P}<.05)$ compared to the PPA group. At six months both the NSE and NSEB groups had decreased pain after the NME test compared to the PPA group $(\mathrm{p}=.04) .($ Table 5$)$

\section{Kinesiophobia}

TSK score did not significantly differ between groups $(P>.12)$. From baseline to the six-month follow-up, the NSE group showed significant improvements in the total TSK-11 score, and on the subscales for activity avoidance and somatic focus $(P<.01)$. Over this time period, the NSEB group only showed improvement on the activity avoidance subscale $(P<$ 


\section{Patient Satisfaction}

At the six-month follow-up, 55\% of the NSE group and 67\% of the NSEB group reported that they were very satisfied with their treatment (score of 6 and 7 on the Likert scale). These proportions were significantly greater than in the PPA group $(19 \% ; P<.01)$.

\section{Exercise Compliance}

Compliance to exercise did not significantly differ between groups at three $(P=.07)$ or six months $(P<.90)$ (Table 3$)$.

\section{DISCUSSION}

The present findings suggest that neck-specific exercise has positive effects on neck endurance in patients with chronic WAD. Both neck-specific exercise groups (NSE and NSEB) showed significant improvements in dorsal muscle endurance, which were not observed in the PPA group. Pain intensity immediately following endurance testing was decreased at six months in the NSE and NSEB groups. These results indicated that neckspecific exercise can improve the capacity to tolerate sustained loading of the neck, which is a problem in individuals with WAD. ${ }^{7,38}$ While general exercises show benefits in modulating 17 and preventing ${ }^{18,19}$ chronic pain, they don't appear to specifically address the motor deficits in patients with WAD. ${ }^{4-6}$

Previous RCT studies including chronic WAD patients have concluded that exercise does not improve function ${ }^{15,26}$ and that advice is equally effective compared to a comprehensive exercise program ${ }^{39}$ or individualized exercise ${ }^{27}$ However, this neck-specific exercise program (NSE and NSEB) targeted at improving the endurance of the deep flexor, rotator, and extensor muscles, was also beneficial in improving neck function and reducing analgesic drug. ${ }^{29}$ Compared to participants in the PPA intervention, individuals within both neck-specific exercise groups also tended to be more compliant with their recommended 
exercise program (this difference approached significance) and reported higher levels of satisfaction with their exercise intervention. The quality of treatment recommendations and information (including cause, prognosis and prevention) were reported as important factors for patient satisfaction with treatment ${ }^{40}$ suggesting that individuals with WAD may perceive neck-specific exercise to be more relevant to their condition than PPA.

In contrast to our original hypothesis, our present findings did not show improved outcomes when a behavioral approach added to the exercise intervention. The NSEB group experienced a more rapid improvement in dorsal muscle endurance. We had anticipated that the addition of a behavioral approach would improve the benefits of neck-specific exercise by potentially reducing the individual's kinesiophobia and the associated negative effects on exercise. However, TSK score did not differ between groups. Only the NSE group showed improvements on both TSK subscales and on the total TSK measures over time. In contrast, the NSEB group showed improvement only on the activity avoidance subscale. It is possible that non-provocative neck-specific exercises may also be beneficial in reducing fear of movement in WAD. However, the presently observed improvements in TSK were small, and TSK scores at baseline were relatively low. This indicates that kinesiophobia may not have been of significant clinical concern for the participants in the present study, which would make it difficult to detect clinically important change. ${ }^{41}$

\section{Study Limitations}

The present study has several limitations. Improvements in neck muscle endurance were not observed across all conditions. Men in the NSE and NSEB group showed significantly enhanced ventral NME at six months follow-up. However, there was not a significant group by time interaction effect for dorsal NME for men so the results should be interpreted with caution. Future studies must consider whether the ventral neck muscle 
exercises used in this study were the most appropriate compared to other exercise programs that have reportedly led to improvements. ${ }^{42,43}$

Overall, using endurance measures similar to those used in previous studies, here we recorded lower neck muscle endurance capacity than previously reported in healthy individuals ${ }^{34,44}$ and in cases of non-specific neck pain, ${ }^{35,44}$ especially for the dorsal neck muscles. Baseline measurements showed that women in the present study only had $10 \%$ (dorsal muscles) and $52 \%$ (ventral muscles) of the NME reported in healthy individuals, ${ }^{34}$ while men showed $18 \%$ (dorsal muscles) and $46 \%$ (ventral muscles) of the NME values. ${ }^{34}$ At the six-month follow-up, both the NSE and NSEB groups showed improved NME, but these values were still much lower compared to those reported in healthy individuals for both dorsal (women, $22 \%$; men, $35 \%$ ) and ventral neck muscles (women, $63 \%$; men, $51 \%$ ). ${ }^{34}$ These findings, together with the observed inconsistent improvements in endurance in response to exercise, suggest that individuals with chronic WAD may require a longer training period to maximize improvements in endurance compared to patients with nonspecific neck pain.

It must also be noted that the present findings are limited to the presently delivered exercise programs and behavior intervention. The gold standard for an RCT design would involve blinded investigators and participants, but it is not possible to blind patients/providers in exercise studies. This may have impacted the results if the participants and/or physiotherapists were influenced by their perceptions regarding the type of exercise program they were undertaking (NSE, NSEB, or PPA programs). Our findings suggest the participants had similar expectations for all three exercise programs (Table 1), but it cannot be excluded that the differences in consultation time with therapists between the exercise interventions may have affected findings. Limitations of the prescribed exercise approaches could have 
behavioral interventions may have been more successful in reducing kinesiophobia and enhancing the effects of exercise compared to the effects demonstrated in this study. Future studies should investigate potentially better strategies for training ventral neck muscles as well as improving fear of movement and re-injury. The generalizability of the present study may be further limited by the fact that $23 \%$ of participants were lost to follow-up at six months. However, drop-out analysis showed no significant differences between participants who dropped out and those who completed the study.

\section{Conclusions}

In conclusion, among individuals with chronic WAD, neck-specific exercises resulted in greater gains in neck muscle endurance, decreased pain intensity immediately following endurance testing and greater patient satisfaction compared to prescribed physical activity. These findings suggest that neck-specific exercises should be considered as part of the total management plan for individuals with persistent pain and disability after a whiplash injury. Addition of the behavioral approach to exercise led to a more rapid improvement in dorsal muscle endurance, but no other effects.

\section{ACKNOWLEDGEMENTS}

This study was financially supported by the Swedish government in cooperation with the Swedish Social Insurance Agency through the REHSAM Foundation RS2010/009, Centre for Clinical Research Sörmland at Uppsala University Sweden and Uppsala-Örebro Regional Research Council Sweden. Shaun O'Leary was supported by a Health Practitioner Research Fellowship from Queensland Health and the University of Queensland (NHMRC CCRE Spinal Pain, Injury, and Health). Anneli Peolsson was supported by the Swedish Research Council and the Wennergren Foundation. 
REFERENCES

395

1. Carroll LJ, Holm LW, Hogg-Johnson S, Cote P, Cassidy JD, Haldeman S, et al. Course and prognostic factors for neck pain in whiplash-associated disorders (WAD): results of the Bone and Joint Decade 2000-2010 Task Force on Neck Pain and Its Associated Disorders. J Manipulative Physiol Ther 2009;32:S97-S107.

400

2. Leth-Petersen S, Rotger GP. Long-term labour-market performance of whiplash claimants. J Health Econ. 2009;28:996-1011.3.

403 3. Holm LW, Carroll LJ, Cassidy JD, Hogg-Johnson S, Cote P, Guzman J, et al. The burden and determinants of neck pain in whiplash-associated disorders after traffic collisions: results of the Bone and Joint Decade 2000-2010 Task Force on Neck Pain and Its Associated Disorders. Spine. 2008;33:S52-9. system dysfunction following whiplash injury. Pain. 2003;103:65-73.

409

5. Jull G, Kristjansson E, Dall'Alba P. Impairment in the cervical flexors: a comparison of whiplash and insidious onset neck pain patients. Man Ther. 2004;9:89-94.

412 6. Woodhouse A, Liljeback P, Vasseljen O. Reduced head steadiness in whiplash compared with non-traumatic neck pain. J Rehabil Med. 2010;42:35-41.

$4147 . \quad$ Kumbhare DA, Balsor B, Parkinson WL, Harding Bsckin P, Bedard M, Papaioannou A, et al. Measurement of cervical flexor endurance following whiplash. Disabil Rehabil. 2005;27:801-7. 
417 8. Yu LJ, Stokell R, Treleaven J. The effect of neck torsion on postural stability in subjects with persistent whiplash. Man ther. 2011;16:339-43.

9. Panjabi MM. The stabilizing system of the spine. Part I. Function, dysfunction, adaptation, and enhancement. J Spinal Disord. 1992;5:383-9.

10. Mayoux-Benhamou MA, Revel M, Vallee C, Roudier R, Barbet JP, Bargy F. Longus colli has a postural function on cervical curvature. Surg Radiol Anat. 1994;16:367-71.

11. Kristjansson E, Jonsson H. Is the sagittal configuration of the cervical spine changed

15. Vikne J, Oedegaard A, Laerum E, Ihlebaek C, Kirkesola G. A randomized study of new sling exercise treatment vs traditional physiotherapy for patients with chronic whiplash-associated disorders with unsettled compensation claims. J Rehabil Med. 2007;39:252-9.

16. Bunketorp L, Lindh M, Carlsson J, Stener-Victorin E. The effectiveness of a supervised physical training model tailored to the individual needs of patients with whiplash-associated disorders--a randomized controlled trial. Clin Rehabil. 2006;20:201-17. 
441 17. Bartholomew JB, Lewis BP, Linder DE, Cook DB. Post-exercise analgesia: replication and extension. J Sports Sci. 1996;14:329-34.

18. Sluka KA, O'Donnell JM, Danielson J, Rasmussen LA. Regular physical activity prevents development of chronic pain and activation of central neurons. J Appl Physiol. 2013;15:725-33

19. Swedish NIoPH. Physical activity in the prevention and treatment of disease. Stockholm: Swedish National Institute of Public Health; 2010.

20. Sullivan MJ, Stanish W, Sullivan ME, Tripp D. Differential predictors of pain and

23. Nijs J, Van Oosterwijck J, De Hertogh W. Rehabilitation of chronic whiplash: treatment of cervical dysfunctions or chronic pain syndrome? Clin Rheumatol. 2009;28:243-51.

24. Louw A, Diener I, Butler DS, Puentedura EJ. The effect of neuroscience education on pain, disability, anxiety, and stress in chronic musculoskeletal pain. Arch Phys Med Rehabil. 2011;92:2041-56. 
25. Glanz K, Rimer BK, Viswanath K. Health behavior and health education : theory, research and practice. San Francisco: Jossey-Bass; 2008.

26. Soderlund A, Lindberg P. Cognitive behavioural components in physiotherapy management of chronic whiplash associated disorders (WAD)--a randomised group study. G Ital Med Lav Ergon. 2007;29:5-11.

27. Stewart MJ, Maher CG, Refshauge KM, Herbert RD, Bogduk N, Nicholas M. Randomized controlled trial of exercise for chronic whiplash-associated disorders. Pain. 2007;128:59-68.

28. Peolsson A, Landen Ludvigsson M, Overmeer T, Dedering A, Bernfort L, Johansson $\mathrm{G}$, et al. Effects of neck-specific exercise with or without a behavioural approach in addition to prescribed physical activity for individuals with chronic whiplashassociated disorders: a prospective randomised study. BMC Musculoskelet Disord. $2013 ; 14: 311$.

29. Ludvigsson ML, Peterson G, O'Leary S, Dedering A, Peolsson A. The Effect of Neck-specific Exercise with, or without a Behavioral Approach, on Pain, Disability and Self-efficacy in Chronic Whiplash-associated Disorders: A Randomized Clinical Trial. Clin J Pain, 2014.

30. Spitzer WO, Skovron ML, Salmi LR, Cassidy JD, Duranceau J, Suissa S, et al. Scientific monograph of the Quebec Task Force on Whiplash-Associated Disorders: redefining "whiplash" and its management. Spine. 1995;20:1-73.

31. Carlsson AM. Assessment of chronic pain. I. Aspects of the reliability and validity of the visual analogue scale. Pain. 1983;16:87-101.

32. Vernon H, Mior S. The Neck Disability Index: a study of reliability and validity. J Manipulative Physiol Ther. 1991;14:409-15. 
33. Edmondston S.J, Wallmurod ME, Macleid F, Kvamme LS, Joebges S, Brabham GC. Reliability of isometric muscle endurance tests in subjects with postural neck pain. $\mathrm{J}$ Manipulative Physiol Ther. 2008; 31:348-54.

34. Peolsson A, Almkvist C, Dahlberg C, Lindqvist S, Pettersson S. Age- and sex-specific reference values of a test of neck muscle endurance. J Manipulative Physiol Ther. 2007;30:171-7.

35. Peolsson A, Kjellman G. Neck muscle endurance in nonspecific patients with neck pain and in patients after anterior cervical decompression and fusion. $\mathbf{J}$ Manipulative Physiol Ther. 2007;30:343-50.

36. Roelofs J, Sluiter JK, Frings-Dresen MH, Goossens M, Thibault P, Boersma K, et al. Fear of movement and (re)injury in chronic musculoskeletal pain: Evidence for an invariant two-factor model of the Tampa Scale for Kinesiophobia across pain diagnoses and Dutch, Swedish, and Canadian samples. Pain. 2007;131:181-90.

37. Vernon H. The Neck Disability Index: state-of-the-art, 1991-2008. J Manipulative Physiol Ther. 2008;31:491-502.

38. Peolsson A, Ludvigsson ML, Wibault J, Dedering A, Peterson G. Function in patients with cervical radiculopathy or chronic whiplash-associated disorders compared with healthy volunteers. J Manipulative Physiol Ther. 2014;37:211-8.

39. Michaleff ZA, Maher CG, Lin CW, Rebbeck T, Jull G, Latimer J et al. Comprehensive physiotherapy exercise programme or advice for chronic whiplash (PROMISE): a pragmatic randomised controlled trial. Lancet. 2014;384:133-41.

40. Leininger BD, Evans R, Bronfort G. Exploring patient satisfaction: a secondary analysis of a randomized clinical trial of spinal manipulation, home exercise, and medication for acute and subacute neck pain. J Manipulative Physiol Ther. 2014;37:593-601. 
41. Hapidou EG, Obrien MA, Pierrynowski MR, de Las Heras E, Patel M, Patla T. Fear and Avoidance of Movement in People with Chronic Pain: Psychometric Properties of the 11-Item Tampa Scale for Kinesiophobia (TSK-11). Physiother Can. 2012;64:23541.

42. Falla D, O'Leary S, Farina D, Jull G. The Change in Deep Cervical Flexor Activity After Training Is Associated With the Degree of Pain Reduction in Patients With Chronic Neck Pain. The Clinical journal of pain. 2011;28:628-34.

43. Jull GA, Falla D, Vicenzino B, Hodges PW. The effect of therapeutic exercise on activation of the deep cervical flexor muscles in people with chronic neck pain. Manual therapy. 2009;14:696-701.

44. Edmondston S, Bjornsdottir G, Palsson T, Solgard H, Ussing K, Allison G. Endurance and fatigue characteristics of the neck flexor and extensor muscles during isometric tests in patients with postural neck pain. Man ther. 2011;16:332-8.

26

8

9

0

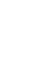

2

(1)

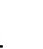

35

36


Table 1. Description of the interventions. For more details see Appendix A, B and C.

\section{Neck-specific exercise (NSE)}

Week 1. Exercise targeted to facilitate the deep neck muscles, (sustain contraction for 3-5 seconds, 3 sets $x$ 5, progress to 3 sets x 10). Advised to exercise daily, 2 to 3 times/day. Basic information regarding neck muscle function provided, but avoid aggravation of pain.

Week 2-3. Neck-specific exercise with isometric resistance in supine, progress to sitting position, (sustain contraction 3 to 5 seconds, 3 sets x 5, progress to 3 sets x 10). Advised to exercise daily, 2 to 3 times/day.

Information provided regarding postural control and to not aggravate pain.

Introduction to specific gym exercise twice weekly.

Week 3-12. Neck-specific gym exercise in weighted pulley, starting load 0.25 to $0.5 \mathrm{~kg}$ (start with 3 sets $x 5$, progress to 3 sets $x 30$ ).

Introduction to home-exercise, the same exercise as in gym but with resistance rubber bands. Exercise in gym 2 times/week and home exercise1 times/week.

Theory underlying NSE program: Whiplash-associated disorders are known to be associated with impaired cervical neck muscle function thought to jeopardize the physical support of the cervical vertebral column. This disruption of physical support may result in subsequent perpetual strain to pain sensitive cervical structures and persistent mechanical neck pain.

Key intent of NSE program: Progressive training of cervical neck muscles to address known impairments with an initial emphasis on facilitating deep cervical muscle activity and subsequent advancement to cervical endurance training. All exercise is performed with minimal aggravation of pain to minimize the deleterious impact of pain and to reduce generalized pain hypersensitivity.

\section{Neck-specific exercise with behavioral approach (NSEB)}

Week 1-2. Specific activity goal setting. Education in neurophysiological and neurobiological processes that can explain aggravating chronic pain. Body awareness techniques for relaxation and postural control. Information in coping strategies to recover from relapse of pain. Neck-specific exercise delivered as for the NSE group but encouraged to continue to exercises despite some pain.

Week 3. Neck-specific exercise with isometric resistance (same as NSE) Education regarding awareness of the influence that thoughts have on behavior.

Week 4-5. Introduction to neck-specific gym and home exercise (same as NSE). Home-exercise including exercises to achieve the specific activity goal and the addition of relaxation techniques. (Exercise in gym 2 times/week and home 1 times/week.)

Introduction to breathing exercise for relaxation.

Week 6-7. Continued gym and home exercise with gradual progression. Repetition and reinforcement of pain education from week 1 . 
Week 8-10. Continued gym and home exercise with gradual progression. Follow-up of the specific activity goal.

Week 11-12. The participant formulated strategies for dealing with relapse of pain and follow-up of the specific activity goal.

Theory underlying NSEB program: Fear of pain and avoidance of activities that cause pain may jeopardize the successful participation of individuals with WAD in rehabilitative exercise programs and ability to perform daily activities. That may in turn further contribute to the persistence of pain and disability.

Key intent of NSE program: Progressive training of cervical neck muscle function to address known muscle impairments with an initial emphasis on facilitating deep cervical muscle activity and subsequent advancement to cervical endurance training. In contrast to the NSE program, the NSEB program does not emphasis avoidance of pain. Instead it encourages exercise and activity despite pain in an effort to modify behavioral responses considered to perpetuate the persistence of pain.

\section{Prescription of physical activity group (PPA)}

Week 1. Motivational interviewing. Physical examination and individualized physical exercise program. (Neck-specific exercise was not included)

Week 2-12. Continued exercise at home or location outside of health care system. One follow-up with the physiotherapist was possible and the participants could phone the physiotherapist if they had questions.

Theory underlying PPA program: Regular general physical activity can result in a systemic modulation of pain and improved general physical/functional capacity. Physical activity activate descending pain-inhibiting systems and result in decreased pain sensitivity.

Key intent of PPA program: Progressive increase in general physical activity and aerobic fitness. 
Table 2. Baseline variables for the three intervention groups; neck specific exercise, neck specific exercise with behavioral approach and prescription of physical activity.

\begin{tabular}{|c|c|c|c|c|}
\hline Variables & NSE group $(\mathrm{N}=76)$ & NSEB group $(\mathrm{N}=71)$ & PPA group $(\mathrm{N}=69)$ & P-value \\
\hline \multicolumn{5}{|l|}{ Variabel mean (SD)[range] } \\
\hline Age, (years) & $38.1(11.3)[18-62]$ & $40.1(11)[19-63]$ & $42.9(10.7)[18-63]$ & 0.03 \\
\hline BMI kg/m2 & $25.7(4.0)[19-35]$ & $25.9(5.1)[18-45]$ & $26.7(4.9)[19-43]$ & 0.10 \\
\hline Injury duration* & $19.1(8.5)[6-36]$ & $20.3(8.9)[6-36]$ & $19.6(9.7)[6-36]$ & 0.69 \\
\hline \multicolumn{5}{|l|}{ Variables n (\% group) } \\
\hline Gender $\mathrm{n}(\%)$ female & $57(75 \%)$ & $47(66 \%)$ & $38(55 \%)$ & 0.04 \\
\hline Whiplash motor accident ${ }^{\dagger}$ & $65(86 \%)$ & $54(76 \%)$ & $54(82 \%)$ & 0.29 \\
\hline Whiplash other accident ${ }^{\ddagger}$ & $11(14 \%)$ & $17(24 \%)$ & $12(14 \%)$ & 0.29 \\
\hline WAD grade II & $49(64 \%)$ & $33(46 \%)$ & $41(59 \%)$ & 0.08 \\
\hline WAD grade III & $27(36 \%)$ & $38(54 \%)$ & $28(41 \%)$ & 0.08 \\
\hline Previous treatment ${ }^{\S}$ & $64(85 \%)$ & $57(80 \%)$ & $53(78 \%)$ & 0.37 \\
\hline Work full-time & $43(56 \%)$ & $36(51 \%)$ & $37(54 \%)$ & 0.72 \\
\hline \multicolumn{5}{|c|}{ Variables median (IQR) [range] } \\
\hline Expectations NSE ${ }^{\mathbb{I}}$ & $7(6-9)[2-10]$ & $8(7-9)[3-10]$ & $7(5-8)[0-10]$ & 0.38 \\
\hline Expectations NSEB ${ }^{\mathbb{I I}}$ & $7(5-9)[1-10]$ & $7(6-9)[0-10]$ & $7(5-8)[0-10]$ & 0.13 \\
\hline Expectations PPA ${ }^{\mathrm{II}}$ & $7(5-8)[1-10]$ & $7(5-9)[2-10]$ & $7(5-8)[0-10]$ & 0.76 \\
\hline
\end{tabular}

* Months since whiplash injury

${ }^{\dagger}$ Whiplash injury as a result of a motor vehicle accident

† Whiplash injury due to other accidents (e.g. fall, skiing, diving)

$\S$ Sought health care (physician, physiotherapist) for neck pain after the whiplash injury, before entry in the study.

IIExpectation on NSE, NSEB and PPA exercises before treatment; score 0 to 100, higher scores indicating higher expectations. 
NSE; neck specific exercise, NSEB; neck specific exercise with behavioral approach, PPA; prescription of physical activity, BMI; body mass index, WAD; whiplash-associated disorder, NDI; neck-disability index, IQR; interquartile range

Table 3. Additional treatment, adherence to exercise and incidence of new neck

injury for the three intervention groups at three and six months*.

\begin{tabular}{ccccc}
\hline Variables & NSE & NSEB & PPA & P-value \\
\hline $\begin{array}{c}\text { Treatment } \\
\text { 3 months }\end{array}$ & $10(16 \%)$ & $10(16 \%)$ & $11(19 \%)$ & 0.50 \\
6 months & $16(29 \%)$ & $11(24 \%)$ & $15(29 \%)$ & 0.35 \\
& & & & \\
Compliance & & & & \\
3 months & $43(73 \%)$ & $44(74 \%)$ & $19(50 \%)$ & 0.07 \\
6 months & $16(50 \%)$ & $22(53 \%)$ & $20(50 \%)$ & 0.90 \\
Neck injury & & & & \\
3 months & $3(5 \%)$ & $2(3 \%)$ & $4(7 \%)$ & 0.61 \\
6 months & 0 & $1(2 \%)$ & $3(6 \%)$ & 0.14 \\
\hline
\end{tabular}

*Values are number of individuals and percentage per group

$\dagger$ Sought additional treatment due to neck pain.

tCompleted more than $50 \%$ of the recommended intervention sessions.

$\S$ New neck injury from baseline to three and six months follow up.

NSE; neck specific exercise, NSEB; neck specific exercise with behavioral intervention, PPA; prescription of physical activity. 
Table 4. Ventral and dorsal neck muscle endurance (NME) for the three groups; neck specific exercise, neck specific exercise with behavioral approach and prescription of physical activity at baseline, three months and six months follow up.

\begin{tabular}{|c|c|c|c|c|c|c|c|c|c|}
\hline \multirow[b]{2}{*}{ Variable } & \multicolumn{4}{|c|}{ Group, geometric mean, $95 \%$ confidence interval $(95 \% \mathrm{CI})$} & \multicolumn{5}{|c|}{$P$ values* } \\
\hline & Period & NSE & NSEB & PPA & $P_{\mathrm{t}}$ & $P_{\mathrm{g}}$ & $P_{\mathrm{s}}$ & $P_{\mathrm{t}^{* \mathrm{~g}}}$ & $P_{\mathrm{t}^{*} \mathrm{~g} * \mathrm{~s}}$ \\
\hline \multicolumn{10}{|l|}{ Ventral NME $\dagger$} \\
\hline \multirow[t]{3}{*}{ Whole group } & Baseline & $19(15-26)$ & $25(19-32)$ & $22(16-30)$ & & & & & \\
\hline & 3 months & $21(18-28)$ & $29(23-39)$ & $25(19-35)$ & & & & & \\
\hline & 6 months & $28(22-38)$ & $34(26-45)$ & $23(17-32)$ & $<.01$ & .07 & $<.01$ & .13 & $.23 t$ \\
\hline \multirow[t]{3}{*}{ Women } & Baseline & $15(12-22)$ & $18(14-24)$ & $20(13-34)$ & & & & & \\
\hline & 3 months & $19(15-25)$ & $21(17-29)$ & $21(14-34)$ & & & & & \\
\hline & 6 months & $23(18-31)$ & $24(17-34)$ & $24(17-35)$ & & & & & \\
\hline \multirow[t]{3}{*}{ Men } & Baseline & $36(20-66)$ & $41(27-62)$ & $36(21-66)$ & & & & & \\
\hline & 3 months & $37(21-66)$ & $52(34-81)$ & $29(19-46)$ & & & & & \\
\hline & 6 months & $54(30-105)$ & $59(42-87)$ & $22(14-39)$ & & $<.02 \S$ & & & \\
\hline \multicolumn{10}{|l|}{ Dorsal NME $\dagger$} \\
\hline \multirow[t]{3}{*}{ Whole group } & Baseline & $41(29-62)$ & $44(32-63)$ & $42(28-65)$ & & & & & \\
\hline & 3 months & $57(42-79)$ & $64(46-93)$ & $35(23-56)$ & & & & & \\
\hline & 6 months & $86(62-123)$ & $84(60-120)$ & $42(28-66)$ & $<.01$ & .06 & .11 & $<.01$ & $.25 t$ \\
\hline \multirow[t]{3}{*}{ Women } & Baseline & $37(23-59)$ & $34(23-154)$ & $49(28-91)$ & & & & & \\
\hline & 3 months & $53(36-79)$ & $49(32-76)$ & $43(24-78)$ & & & & & \\
\hline & 6 months & $75(50-115)$ & $65(42-102)$ & $55(32-98)$ & & & & $<.02 \mathbb{I}$ & \\
\hline \multirow[t]{3}{*}{ Men } & Baseline & $68(36-132)$ & $67(40-120)$ & $36(21-68)$ & & & & & \\
\hline & 3 months & $71(38-135)$ & $101(56-186)$ & $31(17-60)$ & & & & & \\
\hline & 6 months & $144(74-282)$ & $128(72-234)$ & $35(19-68)$ & & & & $<.02 \mathbb{I}$ & \\
\hline
\end{tabular}

Values are presented as geometric mean (back transformed $\log _{10}$ ) and $95 \%$ confidence interval (CI).

* $\mathrm{P}$ values reported for the; overall change over time $\mathrm{P}_{\mathrm{t}}$; differences between group $\mathrm{P}_{\mathrm{g}}$; differences between gender $\mathrm{P}_{\mathrm{s}}$; interaction between group and time $\mathrm{P}_{t^{*} \mathrm{~g}}$; interaction between time, group and gender $\mathrm{P}_{t^{*}} \mathrm{~g}^{* \mathrm{~s}}$ 
$\dagger$ Neck muscle endurance in seconds for the groups, geometric mean and (95\% CI)

$\$$ P values for the main linear mixed model analyses, group*time*gender interaction effect (group; NSE, NSEB and PPA, time; baseline, three and six months, sex; women and men). The $\mathrm{p}$-values ${ }^{\S \amalg}$ shows the significant differences between groups from the linear mixed model.

$\S$ Significant differences between groups in ventral NME at six months.

II Significant differences between groups in time*group interaction effect in dorsal NME.

NME; neck muscle endurance, NSE; neck specific exercise, NSEB; neck specific exercise with behavioral approach, PPA; prescription of physical activity. 
Table 5. Pain intensity measured immediately prior and following the neck muscle endurance test, the participants self-reported fear of movement for the three intervention groups; neck specific exercise, neck specific exercise with behavioral approach, and prescription of physical activity.

\begin{tabular}{|c|c|c|c|c|c|c|c|c|c|c|c|c|c|c|}
\hline \multirow{2}{*}{ Variables } & \multicolumn{8}{|c|}{ Group median, inter-quartile range (IQR) and range [] } & \multicolumn{6}{|c|}{ Treatment effects and $\mathrm{P}$ values $\dagger$} \\
\hline & & $\mathrm{n}$ & NSE & $\mathrm{n}$ & NSEB & $\mathrm{n}$ & PPA & $\mathrm{P}$ & NSE-PPA & $P$ & NSEB-PPA & $P$ & NSE-NSEB & $P$ \\
\hline \multirow[t]{3}{*}{ VAS before $\mathrm{NME}^{*}$} & Baseline & 76 & $26(14-53)[0-95]$ & 71 & $30(12-53)[0-89]$ & 69 & $32(23-53)[0-94]$ & 0.41 & & & & & & \\
\hline & 3 months & 62 & $17(2-39)[0-97]$ & 66 & $23(4-45)[0-85]$ & 55 & $30(10-57)[0-100]$ & 0.05 & -5.0 & .02 & -3.0 & .16 & -2.0 & .27 \\
\hline & 6 months & 55 & $11(3-11)[0-92]^{*}$ & 59 & $21(5-39)[0-85] *$ & 51 & $24(6-62)[0-91]$ & 0.09 & -7.0 & & -2.0 & & -5.0 & \\
\hline \multirow[t]{3}{*}{ VAS after $\mathrm{NME}^{\S}$} & Baseline & 76 & $33(24-58)[0-97]$ & 71 & $43(17-60)[0-95]$ & 69 & $42(26-63)[4-97]$ & 0.44 & & & & & & \\
\hline & 3 months & 62 & $24(5-48)[0-95]$ & 66 & $32(9-55)[0-98]$ & 55 & $41(21-64)[0-100]$ & 0.03 & -11.0 & .01 & -5.0 & .09 & -6.0 & .39 \\
\hline & 6 months & 52 & $25(6-44)[0-97]^{*}$ & 56 & $27(9-54)[0-77] *$ & 51 & $40(16-48)[0-87]$ & 0.04 & -7.5 & .04 & -5.5 & .05 & -2.0 & .94 \\
\hline \multirow[t]{2}{*}{$\mathrm{TSK}-11^{\mathbb{I}}$} & Baseline & 76 & $22(18-27)[12-37]$ & 71 & $21(17-26)[12-41]$ & 67 & $21(16-28)[12-36]$ & 0.95 & & & & & & \\
\hline & 6 months & 54 & $19(15-23)[11-36]$ & 57 & $19(15-25)[11-40]$ & 52 & $21(15-26)[11-43]$ & 0.47 & -2.5 & & -2.0 & & -0.5 & \\
\hline \multirow[t]{2}{*}{ TSK-AA $^{* *}$} & Baseline & 76 & $12(10-15)[6-22]$ & 71 & $12(9-15)[6-23]$ & 67 & $12(9-15)[6-21]$ & 0.76 & & & & & & \\
\hline & 6 months & 54 & $11(8-14)[5-21]^{*}$ & 57 & $10(8-13)[6-22]^{*}$ & 52 & $12(8-15)[6-23]$ & 0.24 & -2.0 & & -1.0 & & -1.0 & \\
\hline \multirow[t]{2}{*}{$\mathrm{TSK}_{-\mathrm{SF}^{\dagger \dagger}}$} & Baseline & 76 & $9(7-12)[5-17]$ & 71 & $10(7-13)[5-19]$ & 67 & $10(7-12)[5-19]$ & 0.68 & & & & & & \\
\hline & 6 months & 54 & $8(6-10)[5-16] *$ & 57 & $8.5(6-13)[5-18]$ & 52 & $9(6-11)[5-20]$ & 0.27 & -0.5 & & 0.5 & & -1.0 & \\
\hline
\end{tabular}

Values are presented as median, inter-qurtile range (IQR) and range [].

* Significant with-in group differences with respect to time $\mathrm{p}<.05$ 
$\dagger$ Treatments effects at follow-up time (three and six months). If significant between-group differences in the Kruskal-Wallis test are evident, the p-values for post-hoc comparisons are shown. For outcomes; a negative effect favors the first group (the underlined group (NSE-PPA, NSEBPPA, NSE-NSEB).

$\$ \S$ VAS 0 to 100 , higher scores indicating higher pain intensity, median, inter-quartile range (IQR) for the groups measured immediately before $\$$ and after§ the NME tests.

ITSK-11; total score short form, 11 items, from 11 to 44, higher scores indicate higher fear of movement and (re)injury, TSK-AA**; subscale activity avoidance, 5 items, from 5 to 20, TSK-SFtt; subscale somatic focus, 6 items, from 6 to 24 .

NME; neck muscle endurance, NSE; neck specific exercise, NSEB; neck specific exercise with behavioral approach, PPA; prescription of physical activity. 
1

2

3

4

5

6

7 


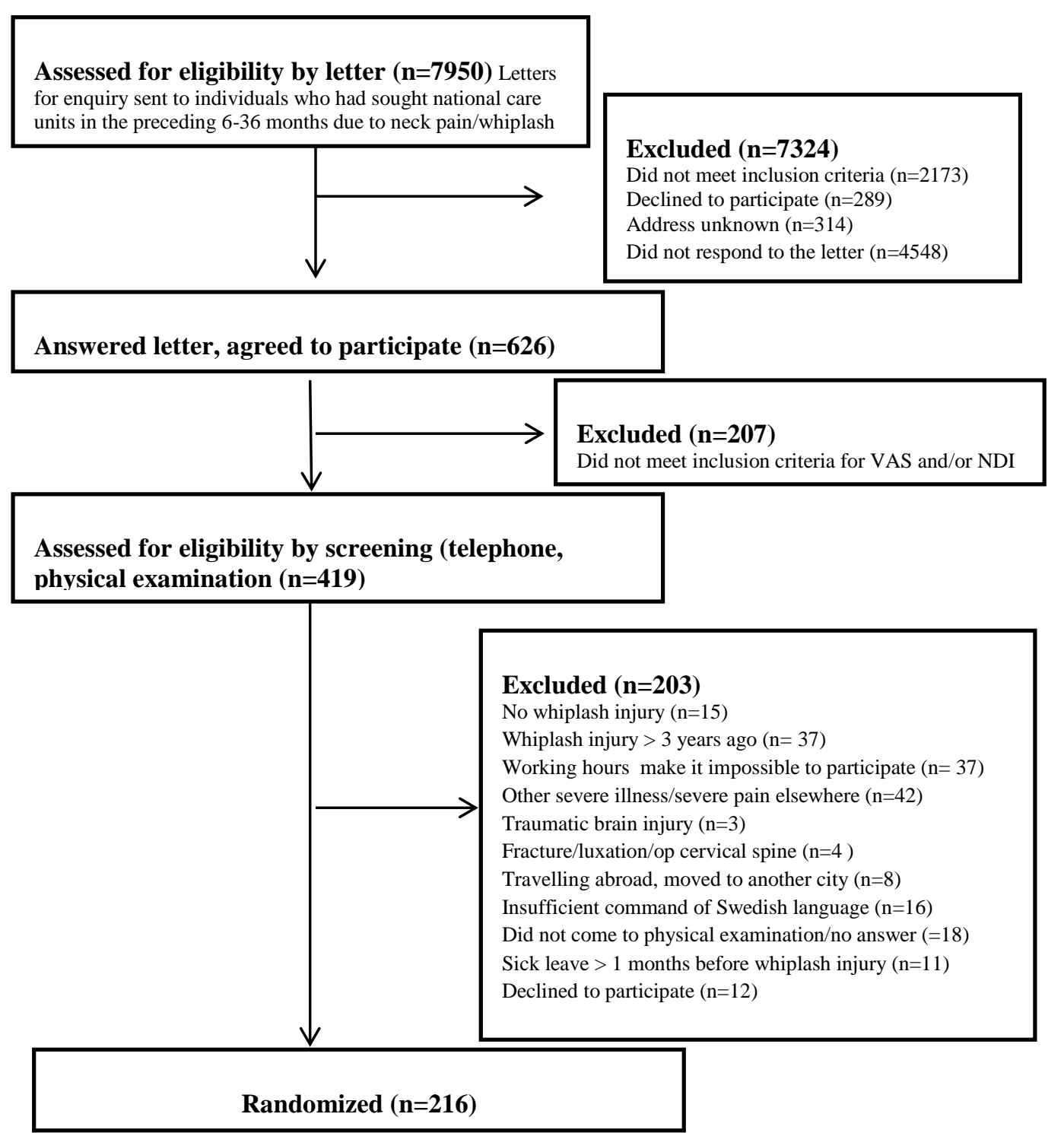

Neck specific exercise (NSE) Allocated to intervention $(n=76)$ Never started intervention $(\mathrm{n}=6)$

\section{Follow-up 3 months}

Lost to follow ups (Lack of time/personal reason $n=6$, more pain after exercise $n=1$, unknown $n=4$, severe disease $n=3$, pregnant $\mathrm{n}=1)(\mathrm{n}=15)$

Analyzed $(n=61 ; 45 / 16)$

\section{Follow-up 6 months}

Lost to follow-up 6 months

(Lack of time/personal reason $n=8$, more pain after exercise $n=1$, unknown $n=10$, severe disease $n=3$ ) $(n=22)$

Analyzed (n=54; 39/15)
Neck specific exercise with behavior intervention (NSEB)

Allocated to intervention $(n=71)$

Never started intervention $(n=3)$

Follow-up 3 months

Lost to follow-up 3 months (Lack of time/personal reason $n=2$, unknown $n=1$, moved $n=1)(n=4)$

Analyzed ( $n=67 ; 44 / 23)$

Follow-up 6 months

Lost to follow-up 6 months (Lack of time/personal reason $n=4$, more pain after exercise $n=1$, unknown $n=4$, moved $n=2)(n=11)$

Analyzed (n=60; 39/21)
Prescribed physical activity (PPA)

Allocated to intervention $(n=69)$

Never started intervention $(n=5)$

\section{Follow-up 3 months}

Lost to follow-up 3 months (Lack of time/personal reason $n=5$, unknown $n=3$, severe disease $n=4$ ) $(\mathrm{n}=12)$

Analyzed (n=57; 29/28)

\section{Follow-up 6 months}

Lost to follow-up 6 months (Lack of time/personal reason $n=6$, more pain after exercise $n=1$, pregnant $n=1$, unknown $n=4$, moved $n=1$, severe disease $n=5$ ) $(\mathrm{n}=18)$

Analvzed (n=51:23/28)

Fig 1. Flow diagram of participant recruitment and retention $(\mathrm{n}=$ total number; women/men). 


\section{APPENDIX A}

\section{Neck-Specific Exercise (NSE) Group}

Current recommendations for treatment of chronic whiplash-associated disorder include nonprovocative exercise regimens ${ }^{1}$ to avoid symptom exacerbation. In accordance, the participants in the NSE group were instructed to avoid pain aggravation during exercise. In addition to neck-specific exercises, this program included exercises for the shoulder girdle (axio-scapular muscles), low back, and abdomen, as well as stretching exercises.

\section{Week 1}

- Neck-specific exercise (Appendix B) aiming to facilitate deep neck muscles.

- Provision of basic information regarding neck muscle function and the importance of exercising daily but avoiding pain aggravation.

\section{Weeks 2-3}

- Provision of information regarding the use of good body posture to minimize postural strain.

- Isometric neck-specific exercises in the supine and sitting positions.

- Introduction to neck-specific gym exercise (Appendix C).

\section{Weeks 3-12}

- Continued training with gradual progression.

\section{Week 12}

- Prescription of physical activity, instructions to continue with neck-specific and general exercise outside of the physiotherapy clinic. 


\section{Neck-Specific Exercise with Behavioral Approach (NSEB) Group}

The behavioral intervention in this study was based on social cognitive theory (SCT) and the trans-theoretical model (TTM). ${ }^{2}$ Behavior changes are motivated by beliefs about the consequences of one's behavior (e.g. fear of pain and/or (re)injury) and the ability to perform an activity despite pain. SCT methods for behavioral change include goal setting, enhancing the knowledge and skills needed to perform a given behavior, performing the given activity in small steps to ensure success (graded activity), stress management training, and learning strategies to deal with pain relapse. The TTM focuses on five stages of behavior change, including maintenance of an already changed health behavior (e.g. continuing to exercise).

\section{Weeks 1-2}

- Specific activity goal setting. The participants formulated three specific activity goals to improve daily activities at work, during leisure time, and during physical exercise. The participants chose activities that they had difficulties undertaking due to neck pain or due to the fear of aggravating neck pain. The goals were designed to be achievable during the 12-week rehabilitation program (e.g. 20 minutes of computer work performed 5 days a week).

- Education in neurophysiological and neurobiological processes underlying chronic pain.

- Provision of information regarding coping strategies and recovering from pain relapse.

- Neck-specific exercises (Appendix B) aiming to facilitate deep neck muscles.

- Instructions in relaxation exercises and body awareness techniques for postural control. 


\section{Week 3}

- Isometric neck-specific exercises performed in the supine and sitting positions.

- Introduction to self-monitoring and awareness of the influences of thoughts on behavior.

\section{Weeks 4-5}

- Introduction to neck-specific gym exercise (Appendix C).

- Specific activity goal exercise.

- Breathing exercises.

\section{Weeks 6-7}

- Continued training with gradual progression.

- Reinforcement of education regarding the neurophysiological and neurobiological processes in chronic pain.

\section{Weeks 8-10}

- Follow-up of specific activity goal exercises, and continuation of neck-specific gym exercises.

\section{Weeks 11-12}

- Strategies for dealing with neck pain relapse.

- Follow-up of specific activity goal exercise.

- Prescription of physical activity, and instructions to continue with exercise outside of the physiotherapy clinic.

\section{Prescription of Physical Activity (PPA) Group}

Physical activity was prescribed with the aim of increasing general physical activity and aerobic fitness in order to decrease pain. Physical activity is considered to be of great benefit in the rehabilitation of patients with persisting pain. ${ }^{3}$ Such physical activity must be 
performed regularly for at least 10 minutes, and should be of at least moderate intensity. ${ }^{1}$ The instructional session for the PPA group was 60 minutes long, with the possibility of one additional 30-minute follow-up session.

\section{Week 1}

- Physical examination and motivational interviewing.

- Individualized physical exercise program, not including neck-specific exercises.

\section{Weeks 2-12}

- Physical exercises at home or at a selected location outside of the health care system (eg, a gym), with the possibility of one follow-up with the physiotherapist.

- The participants were permitted to phone the physiotherapist if they wished to ask questions during the first 12 weeks.

References:

1. Jull GA, Whiplash, headache, and neck pain : research-based directions for physical therapies 2008, Edinburgh ;: Churchill Livingstone.

2. Glanz K, Rimer BK, andViswanath $\mathrm{K}$, Health behavior and health education : theory, research and practice 2008, San Francisco: Jossey-Bass.

3. Physical activity in the prevention and treatment of disease2010, Stockholm: Swedish National Institute of Public Health. 


\section{APPENDIX B}

\section{Neck-Specific Exercises}

Neck-specific exercises were performed in the supine position. The physiotherapist instructed the patient to very slightly press their neck in the direction of the physiotherapist's fingers. During these exercises, the patient was asked to try to minimize their contraction of the superficial neck muscles (m. trapezius, m. sternocleidomastoid, or m. scalene muscles). It was crucial to establish a correct movement pattern before the patient started home exercises.

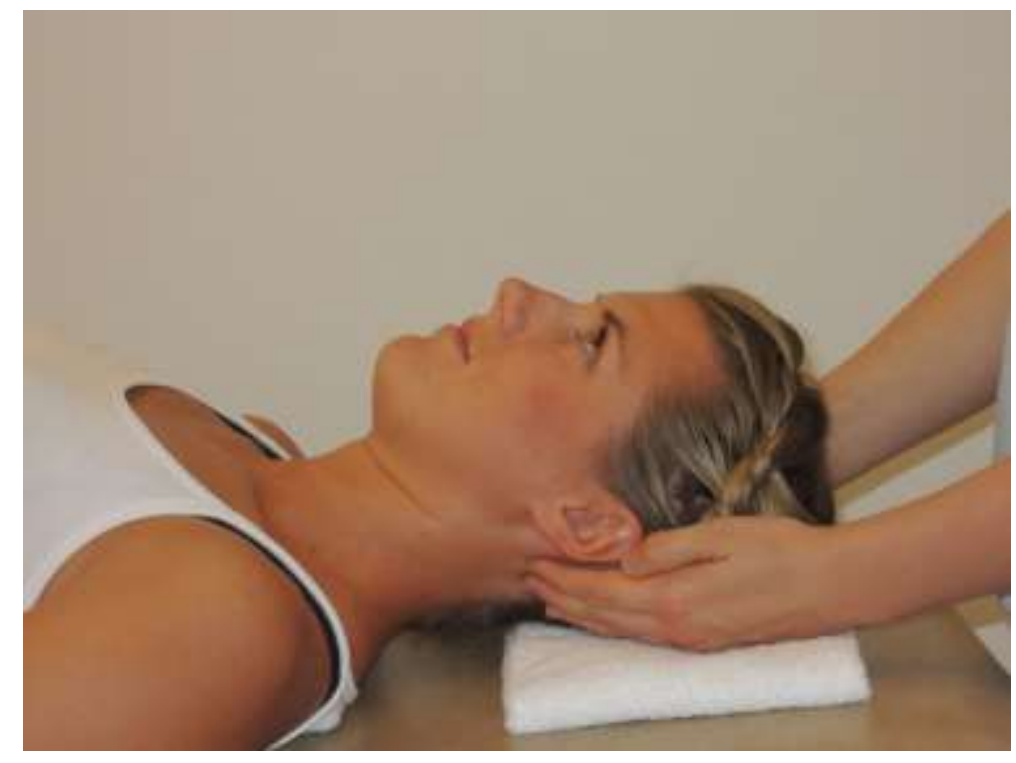

Appendix B Fig 1. Isometric Extension: The patient was instructed to feel the gentle touch from the physiotherapist's palpation.. The patient was told to think of the movement as "if you perform a neck extension but do not move your head. Move your eyes in that directionup (over your head)" and hold the contraction for 3 to 5 seconds. 


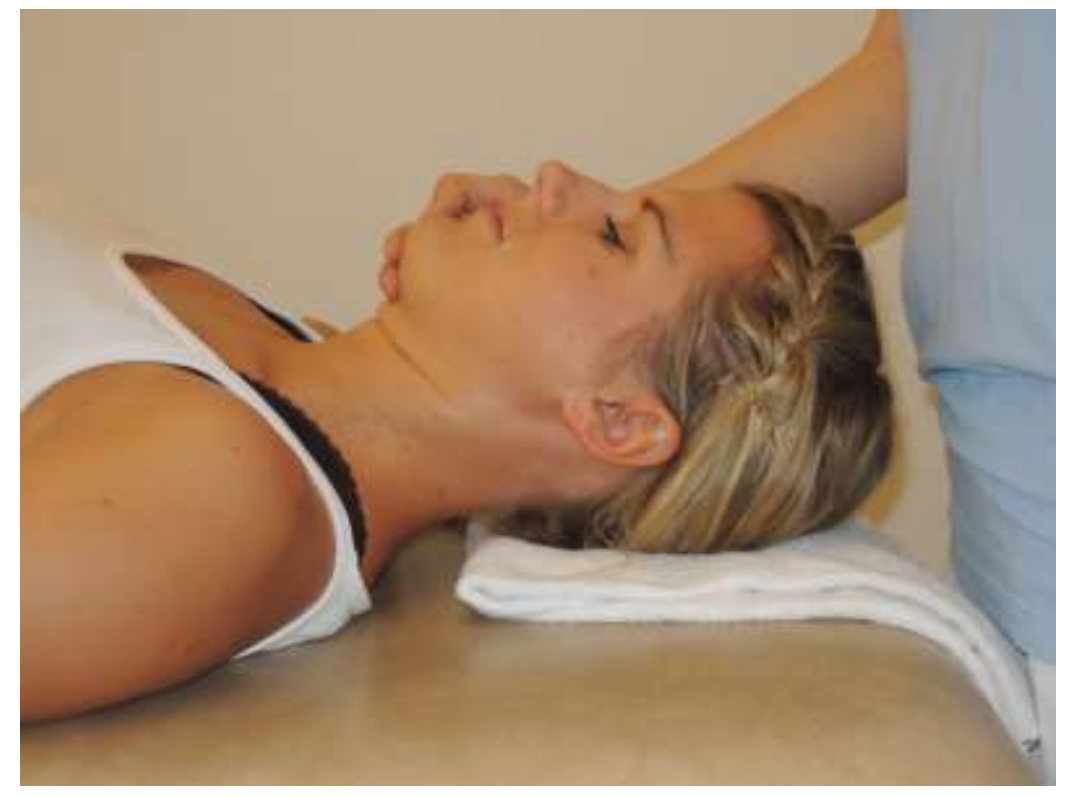

Appendix B Fig 2. Isometric Flexion: In the starting head position, the patient was instructed to relax their jaw, keeping their lips together but teeth apart and their tongue relaxed. The physiotherapist's fingers were placed gently under the patient's chin. The patient was instructed to "Perform a gentle nod, slightly press your chin against my finger but without moving. Move your eyes and look down" and maintain the contraction for 3 to 5 seconds. This exercise was performed with progressive increases of the isometric resistance (pressing the fingers to the chin).

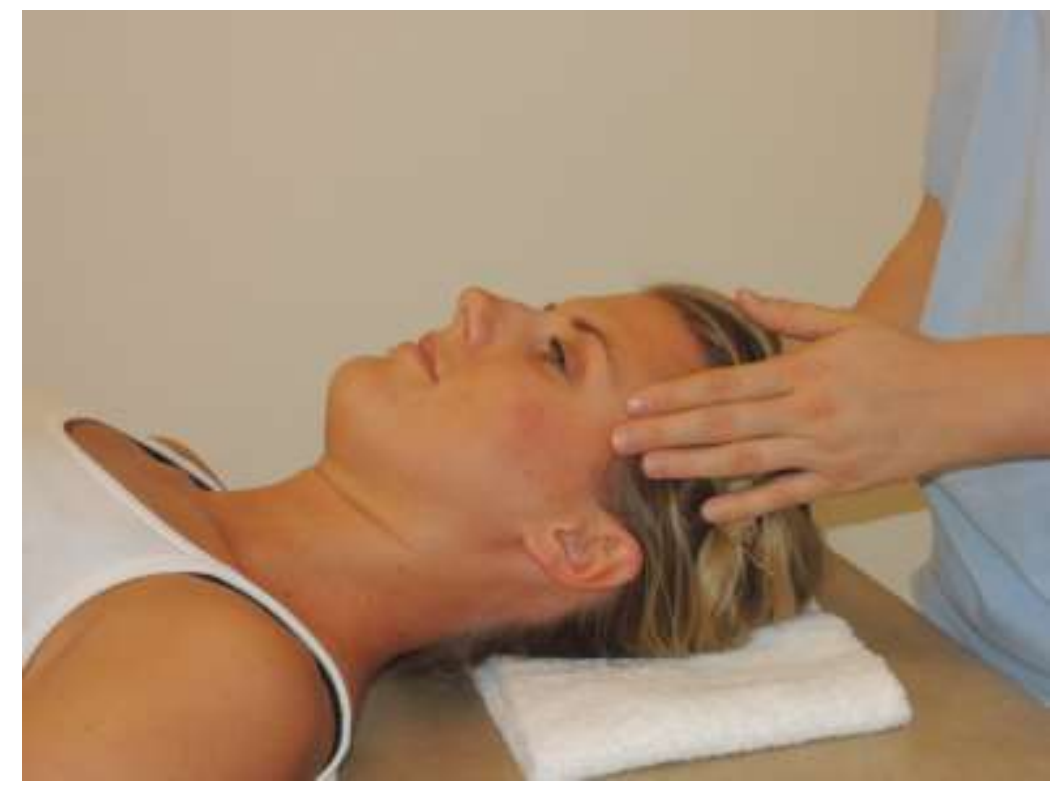


Appendix B Fig 3. Isometric Rotation: The patient was instructed to "Think about rotating your head but do not move your head. Move your eyes and look to the right, and hold still for 3 to 5 seconds. Then move your eyes to the left, and hold still for 3 to 5 seconds". This exercise was performed with progressive increases of isometric resistance (pressing the fingers to the temple).

- Home exercise daily: start with 3 sets of 5 repetitions of each exercise.

- Increase the exercises towards 3 sets of 10 repetitions in the supine and sitting positions. 


\section{APPENDIX C}

\section{Neck-Specific Gym Exercise}

The patients were instructed to maintain a neck position of slight upper cervical flexion and retraction when performing isometric training of the neck muscles in flexion, extension, and lateral flexion. The starting load (weighted pulley) was 0.25 to $0.5 \mathrm{~kg}$. The focus of the exercise was endurance training with a gradually progression of exercise parameters up to 3 sets of 30 repetitions. The physiotherapist chose one of two exercises for flexion (Appendix C Fig 1A or B), extension (Appendix C Fig 1C or D), rotation (Appendix C Fig 1E or 1F) as well as lateral flexion (only one available exercise option) (Appendix C Fig 1G). The participant started with exercise 1B and 1D if they were unable to maintain the neck position (upper flexion and retraction) during the weighted pulleys exercises. The rotation exercise was dynamic, using an elastic rubber band that was gently held between the teeth (Appendix C Fig 1E) or in the supine position with load (Appendix C Fig 1F).

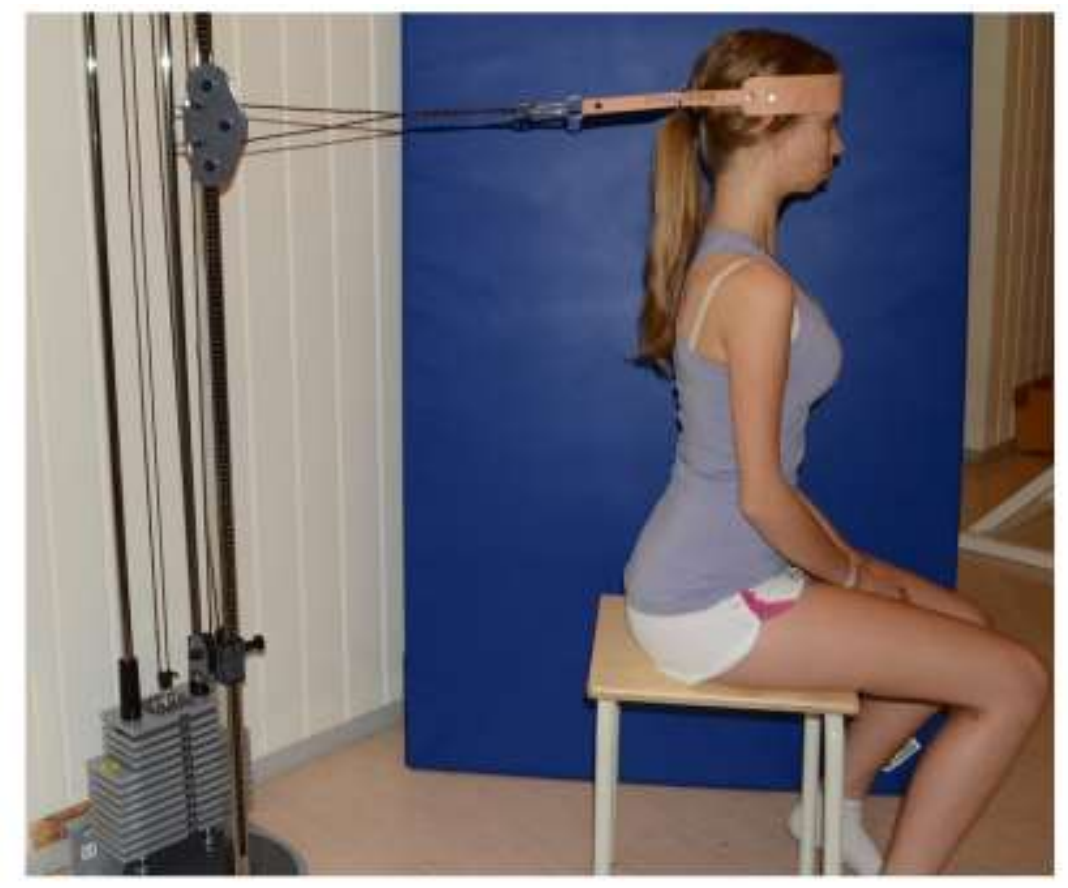

Fig.1a 


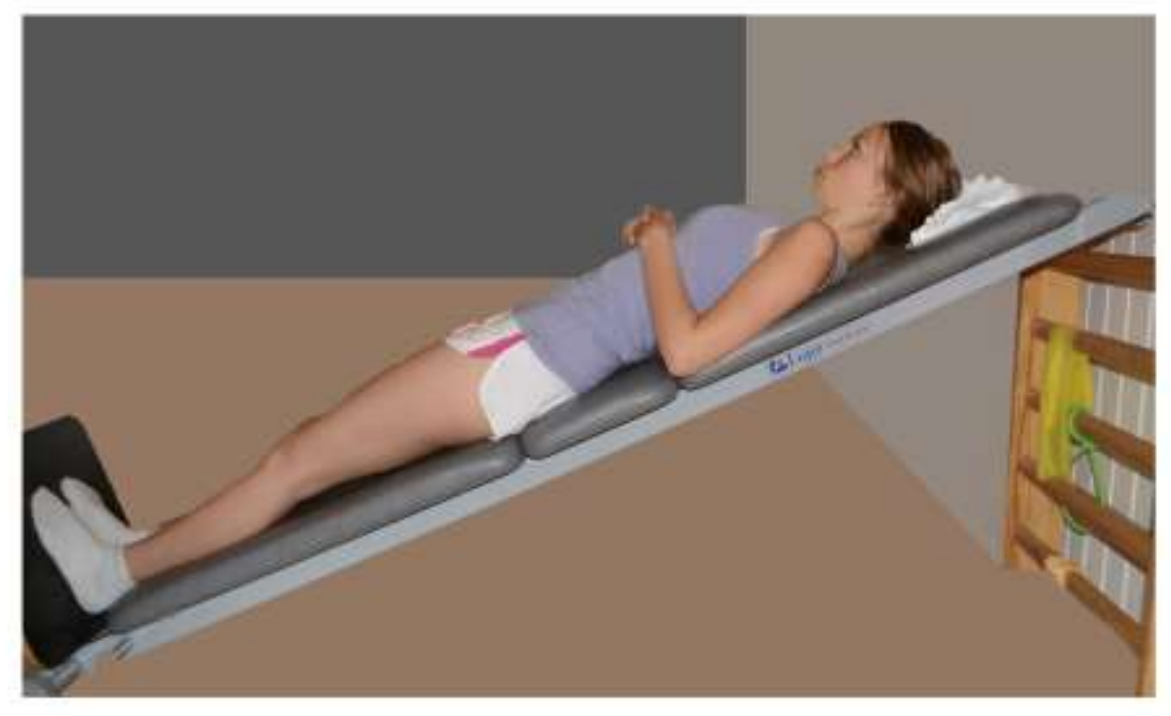

Fig 1b

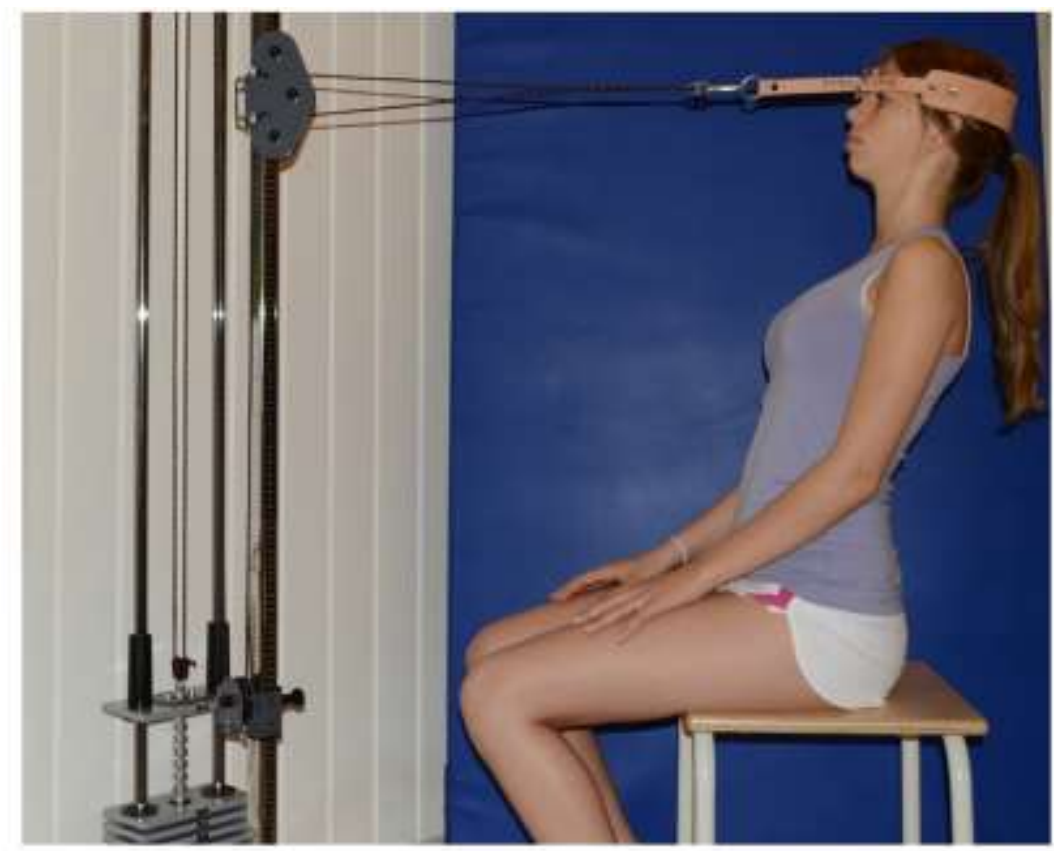

Fig.1c 


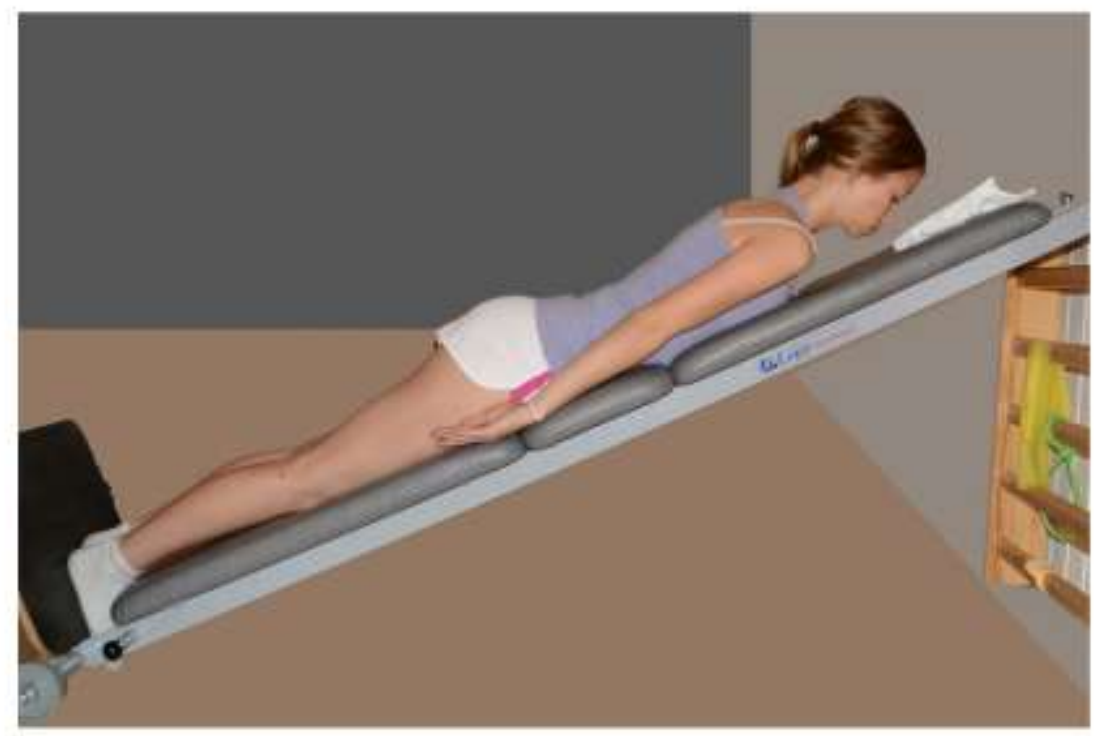

Fig. 1d

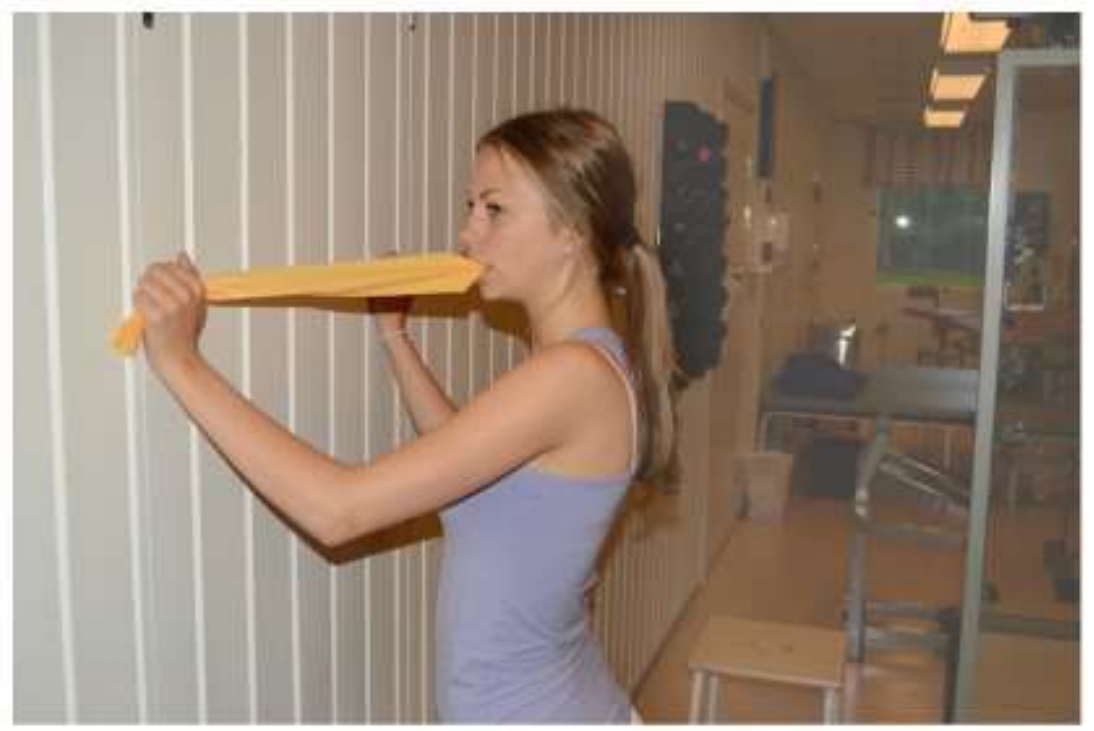

Fig. 1e 


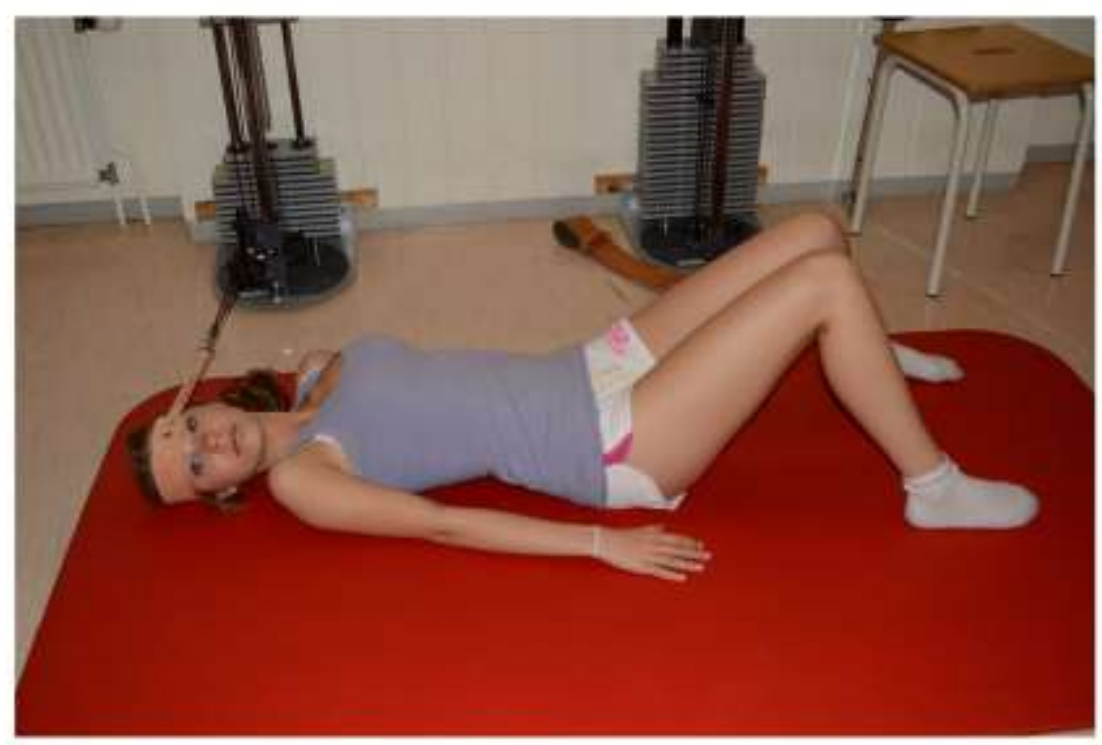

Fig. 1f

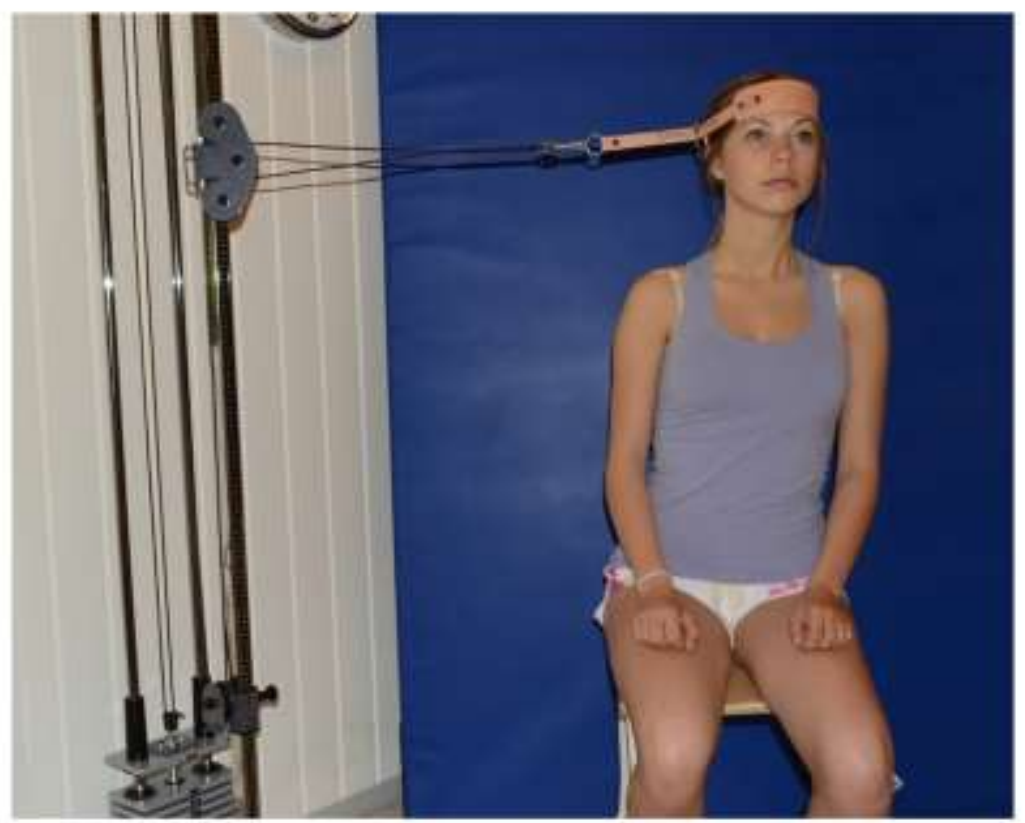

Fig. $1 \mathrm{~g}$

Appendix C Fig 1. For each of the following exercises participants were given the following instructions (and exercise parameters (sets and repetitions)) with the common theme for each 
exercise on maintaining good postural alignment and movement control - A, Lean your body forward, 3 sets $\times 5$ repetitions. B, Lift your head just above the table, 3 sets $\times 5$ repetitions. C, Lean your body backwards, 3 sets $\times 5$ repetitions. D, Lift your head just above the table, 3 sets $\times 5$ repetitions. E, Turn your head to the right, hold 3 to 5 seconds, than move to the left and hold for 3 to 5 seconds, 3 sets $\times 5$ repetitions in each direction. $F$, Turn your head to the right, hold 3 to 5 seconds, then move to the left and hold for 3 to 5 seconds, 3 sets $\times 5$

repetitions in each direction. G, Lean your body away from the pulley (lateral flexion) 3 sets $\times 5$ repetitions to the left and 3 sets $\times 5$ repetitions to the right. 